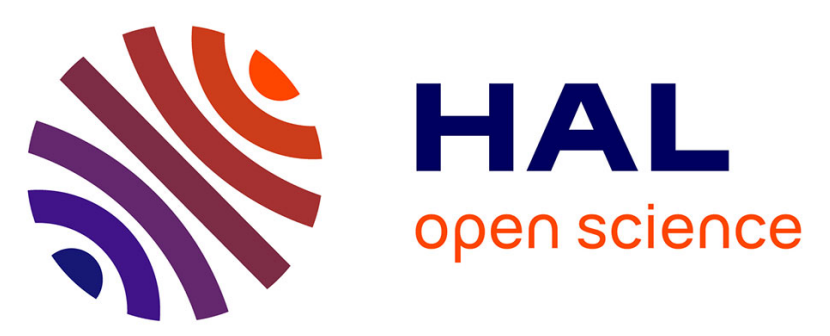

\title{
Substrate-independent luminescent phage-based biosensor to specifically detect enteric bacteria such as E-coli
}

Nathalie Franche, Manon Vinay, Mireille Ansaldi

\section{- To cite this version:}

Nathalie Franche, Manon Vinay, Mireille Ansaldi. Substrate-independent luminescent phage-based biosensor to specifically detect enteric bacteria such as E-coli. Environmental Science and Pollution Research, 2017, 24 (1), pp.42-51. 10.1007/s11356-016-6288-y . hal-01470361

\section{HAL Id: hal-01470361 https://hal.science/hal-01470361}

Submitted on 22 May 2018

HAL is a multi-disciplinary open access archive for the deposit and dissemination of scientific research documents, whether they are published or not. The documents may come from teaching and research institutions in France or abroad, or from public or private research centers.
L'archive ouverte pluridisciplinaire HAL, est destinée au dépôt et à la diffusion de documents scientifiques de niveau recherche, publiés ou non, émanant des établissements d'enseignement et de recherche français ou étrangers, des laboratoires publics ou privés. 


\title{
Substrate independent luminescent phage-based biosensor to specifically detect enteric bacteria such as $E$. coli
}

Nathalie Franche, ${ }^{1}$ Manon Vinay, ${ }^{1 *}$ Mireille Ansaldi ${ }^{1 *}$

\author{
${ }^{1}$ Laboratoire de Chimie Bactérienne, UMR7283, Centre National de la Recherche Scientifique, Aix-Marseille \\ Université, Marseille, France
}

Running Head: Luminescent Phagosensor prototypes, conception and application.

\# Address correspondence to Mireille Ansaldi, mireille.ansaldi@imm.cnrs.fr

* Current address: Biocentric, Bandol, France

\begin{abstract}
Water quality is a major safety consideration in environments that are impacted by human activity. The key challenge of the COMBITOX project is to develop a unique instrument that can accommodate several biodetector systems (see the accompanying COMBITOX papers) able to detect different pollutants such as bacteria, toxins and heavy metals. The output signal chosen by our consortium is based on luminescence detection. Our group recently developed phage-based biosensors using gfp as a reporter gene to detect enteric bacteria in complex environments such as sea water, and the main challenge we faced was to adapt our biodetector to a luminescent signal that could fit the COMBITOX project requirements. Another key point was to use a substrate independent reporter system in order to avoid substrate addition in the detection prototype. This paper describes the development of a phage-based biodetector using a luminescent and substrate independent output to detect some enteric bacteria, such as $E$. coli, in water samples. We have successfully engineered various prototypes using the HK620 and HK97 bacteriophages that use different packaging systems and both proved functional for the integration of the full luxCDABE operon controlled by 2 different bacterial promoters. We show that the luxCDABE operon controlled by the PrplU bacterial promoter is the most efficient in terms of signal emission. The emission of luminescence is specific, and allows the detection of $10^{4}$ bacteria per $\mathrm{ml}$ in 1.5 hours post infection with no concentration nor enrichment step.
\end{abstract}

keywords: biodetector, temperate phage, water quality, luminescence 


\section{Introduction}

Drinking and bathing waters are important vectors of infectious diseases since they constitute important reservoirs for pathogens that belong to different taxa such as viruses, bacteria, eukaryotic parasites and fungi. Pathogens present in waters are able to infect naturally present organisms but also humans, terrestrial and aquatic animals. The variety of bacterial pathogens that affect mariculture systems is important and causes tremendous economic costs (Toranzo et al., 2005). However, the main concern has to do with human health since many human pathogens are found in waters and may cause infectious diseases through ingestion, inhalation or just contact (Pond and World Health Organization, 2005). The oral route is the main way to infections and water quality monitoring is the best way to avoid them. In this case, a vast majority of the bacteria responsible for water driven infectious diseases are enteric bacteria such as Campylobacter, Escherichia coli, Salmonella, Shigella, Yersinia and Vibrio species. Nowadays, it is difficult to rapidly identify specific pathogens, therefore water quality is assessed by looking for indicators of fecal contamination such as $E$. coli and gut enterococci. Ideally, a good indicator must fit to the following criteria: (i) it should develop, or at least, survive in the environment, (ii) it should persist in water and be resistant to the same treatments as pathogens, and (iii) it must be absent, or at very low density, in a non-polluted environment and highly enriched in a contaminated one (Stewart et al., 2008). E. coli and fecal enterococci are the most frequently used indicators. E. coli represents more than $94 \%$ of total coliforms found in animal and human feces and is almost absent in other environments (Edberg et al., 2000). Enterococci are able to grow at $44^{\circ} \mathrm{C}$, are abundant in feces and survive, without dividing, in the environment (Byappanahalli et al., 2012).

Since their discovery (D'Herelle, 2007; Twort, 1915), bacteriophages, the viruses that specifically infect bacteria, have been used as biotechnology and molecular biology tools and therapeutics (Goodridge and Abedon, 2003; Haq et al., 2012; Schmelcher and Loessner, 2014). Several phage-based methods have been developed to detect bacteria using engineered phages. They use a variety of reporter systems that generate fluorescent, luminescent or colorimetric signals (Derda et al., 2013; Edgar, 2006; Loessner et al., 1996; Mosier-Boss et al., 2003; Piuri et al., 2009). The main advantages of the phage systems is that the detection is highly specific and allows to discriminate between alive and dead cells. Our group recently developed a phage-based system couple to flow cytometry that allows specific and highly sensitive detection of enteric bacteria in water samples (Vinay et al., 2015). In order to fit the COMBITOX project requirements (Ansaldi et al., 2015), we decided to adapt our system to luminescence. Indeed, this project aimed to combine several biodetection systems, including toxins, heavy metals and enteric bacteria, within the same automated station. To achieve this goal, our consortium decided to use luminescence as the common output signal. Our main task in this project was thus to adapt our fluorescent phage-based biosensors to luminescence. Several bioluminescence reporter phage systems have been developed so far. Most of them use the reporter genes luxA and luxB genes allowing the production of luciferase without the 
luxCDE genes involved in the production of the luciferase substrate, a fatty aldehyde (Kuhn, 2007; Loessner et al., 1996; Schofield et al., 2009; Waddell and Poppe, 2000). With these biodetectors, the addition of exogenous substrate post-infection is required to detect bacteria. The relatively large size of luxCDABE operon (approximately $6 \mathrm{~kb}$ ) constitute a limitation considering the genome size of a temperate phage (35$60 \mathrm{~kb}$ average) that is packaged into the viral capsid. However, a luxCDABE reporter phage has been recently developed by replacing nonessential genes of the Salmonella temperate phage SPC32H by the entire lux operon (Kim et al., 2014). Phage genomes are packaged according two different packaging mechanisms, the cos and pac systems. In both cases concatemeric phage DNA is used as a substrate for packaging. In cos phages, an enzyme, called terminase, recognizes a specific sequence (cos) that is cut to form cohesive ends. With this system, the size of the packaged DNA is constant. In pac phages, only the first copy of the concatemeric DNA is cut at the pac site position, the following molecules are being packaged through a headful mechanism. The headful packaging system is more tolerant, allowing the packaging of up to $110 \%$ of the size of the phage genome. In this paper, we describe the strategy we used to develop substrate independent reporter phages using both pac and cos phages designed to detect different $E$. coli strains. We have constructed and characterized several prototypes using the HK620 and HK97 bacteriophages that use different packaging systems and both proved functional for the integration of the full luxCDABE operon under the control of the PrplU bacterial promoter. We show that the emission of luminescence is specific, allowing the detection of $10^{4}$ bacteria per $\mathrm{ml}$ in 1.5 hours post infection with no concentration nor enrichment step. Further development will aim to develop phagosensors adapted on demand to the detection of any human or animal pathogen that may be present in surface water. 


\section{Results}

\section{Promoter choice and phage engineering}

The challenge of phage engineering was to integrate the entire lux operon controlled by a strong bacterial promoter and associated with a kanamycin resistance cassette and homology regions of $80 \mathrm{bp}$ at each extremity to allow homologous recombination. Altogether, the DNA fragment size is nearly $8 \mathrm{~kb}$ long (Fig. 1). We made a first construct in phage HK620, which is an E. coli TD2158 specific temperate phage belonging to the Podoviridae family (Dhillon et al., 1998). It packages DNA through a headful mechanism and thus its genome contains pac sites (Clark et al., 2001). We designed two HK620 reporter phages in order to optimize bacterial detection and to obtain a strong luminescent signal. The expression of luxCDABE operon was controlled by either PrpoD or Prp/U promoters, two strong $\sigma 70$ promoters in E. coli. The target region for homologous recombination was chosen in between two convergent genes $h k c E-h k c F$ to avoid the disruption of any transcriptional unit or promoter region. The same region has been successfully used for $g f p$ gene insertion and engineering had no influence on the life cycle of HK620 (Vinay et al., 2015). The construction was done using the $\lambda$ Red recombineering method (Datsenko and Wanner, 2000). Briefly, PCR fragments containing the entire luxCDABE operon under the control of either PrpoD or PrplU promoters associated to the divergently oriented $k^{2} n^{R}$ cassette and flanked by $80 \mathrm{bp}$ of sequence homology with the target sequences (Fig. 1) were electroporated into E. coli LCB6205(HK620) lysogenic strain carrying plasmid pKD46 that allows the production of the $\lambda$ Red recombinase that promotes efficient homologous recombination in $E$. coli (Datsenko and Wanner, 2000). Thus, the insertion of the full size reporter operon under the control of either PrplU or PrpoD promoters in the $h k c E / h k c F$ region gives HK620::PrpoDluXCDABE and HK620::PrplU-luXCDABE recombinant phages (Fig. 1 and construction details in the Material and Methods section). Both recombinant phages were efficiently induced with mitomycin $C(M M C)$, the classical inducer of the SOS response, and produced infectious phage particles (data not shown). Moreover, the presence of the large insertion did not affect the production of the engineered phages since they were produced with equivalent titers compared to the WT phages (data not shown). The bacterial growth and culture luminescence upon infection with the 2 recombinant phages were monitored using a microplate reader (Fig. 2). When E. coli LCB6205 was infected with the WT phage, the luminescence signal was homogenous and was slightly higher from what observed under non-infected conditions. Compared to the growth curve obtained with non infected bacteria, growth profiles of infected bacteria show a re-growth phase post-lysis characteristic of temperate phages. Indeed, during the first 1.5 hours, a slight bacterial growth was observed, immediately followed by a typical lysis phase. Later on, once lysogeny is established, the lysogens grow exponentially until the stationary phase is reached. However, re-growth started 5 hours post-infection with HK620::Prp/U-IUXCDABE versus only 2 hours for WT HK620 or HK620::PrpoD-luxCDABE; Luminescence intensities measured 1.5 hours post-infection were around 1000-folds higher with HK620::Prp/U-IUXCDABE than those measured with WT phage or HK620::PrpoD-luXCDABE. Together, these 
results indicate that the engineered phages are able to infect their host, which in turn produced luminescence. The growth delay observed with HK620::PrplU-luxCDABE might be a consequence of the promoter strength. Indeed, Prp/U is a stronger promoter than PrpoD (Zaslaver et al., 2006), and thus higher amounts of luciferase and substrate are produced when using Prp/U as a promoter. We suspect that their accumulation may be slightly toxic and interfere with early growth. However, it is striking that the PrplU construct generates a much higher luminescence intensity compared to the PrpoD one at a early time point post-infection in agreement with the respective promoter strengths. The PrplU construct was thus chosen for further experiments.

In order to check if the substrate produced by the cells could be a limitation, we performed a similar experiment with decanal addition prior measurement. An infection assay was performed and incubated 2 hours at $30^{\circ} \mathrm{C}$, luminescent was measured prior and after addition of $5 \mu \mathrm{L}$ of $52 \mathrm{mM}$ decanal solution in ethanol 50\%. A luminescent signal of $180680 \pm 9661$ RLU was measured prior decanal addition, whereas the signal measured in the presence of decanal was $156710 \pm 8160 \mathrm{RLU}$. This result indicate that the substrate produced in the cells is not a limitation for the technique. A very important result is that we were able to engineer a $38 \mathrm{~kb}$ genome and produce homogenous and viable phage particles by adding a reporter cassette of $8 \mathrm{~kb}$ without having to remove any part of the original phage genome, suggesting that this phage genome is highly tolerant to size increase.

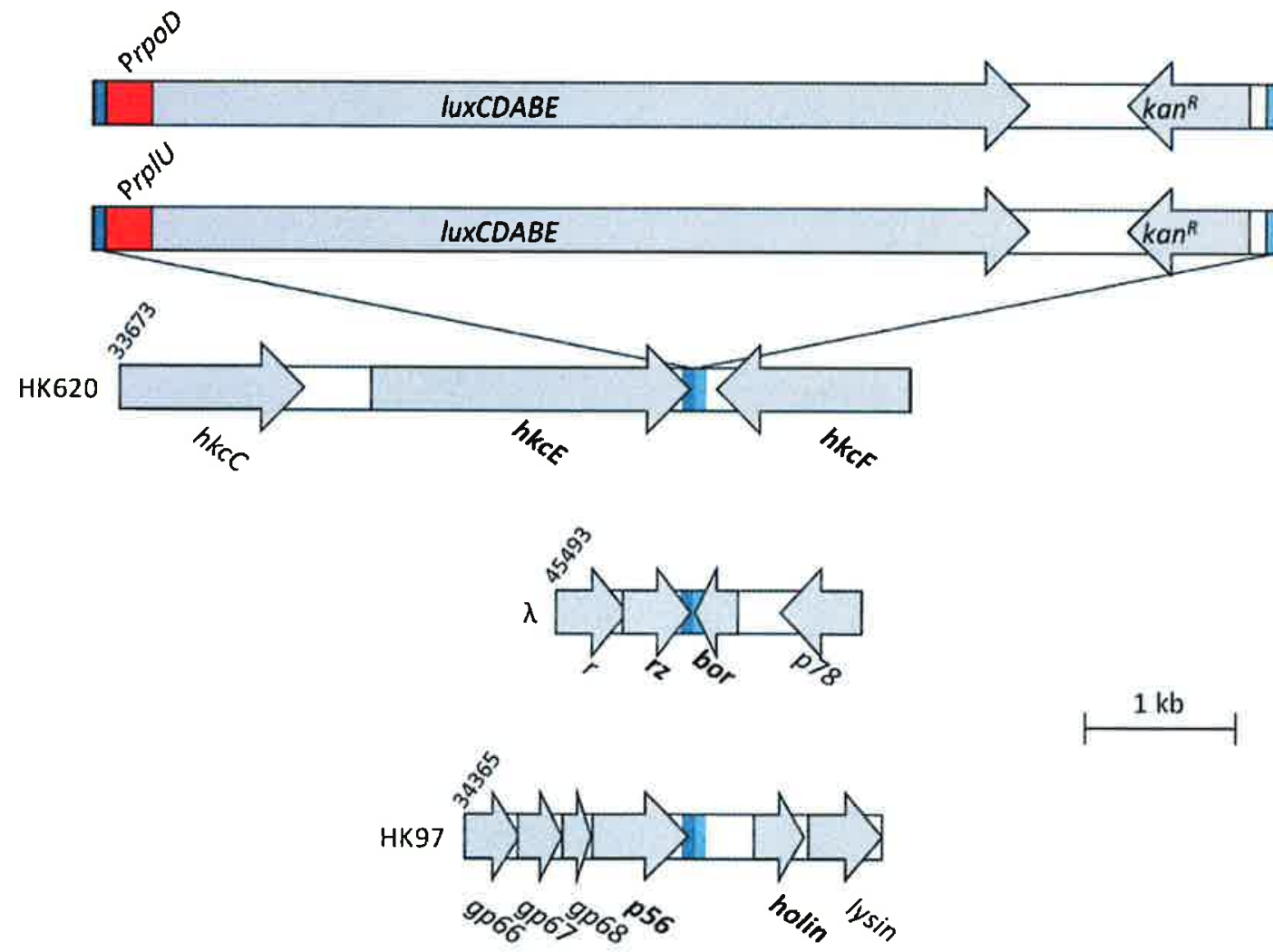

Figure 1. Schematic representation of the strategy to engineer temperate phage genomes. PCR fragments (top) containing the luxCDABE operon under the control of either PrplU ou PrpoD (red) and a kanamycine 
resistance cassette $\left(k^{2} n^{R}\right)$ are flanked by 80 bp homologous (blue) to different intergenic regions in phages HK620 (hkcE/hkcF), $\lambda(r z / b o r)$ and HK97 ( $p 56 / h o l i n)$. Numbers indicate the position on the respective genomes.

A

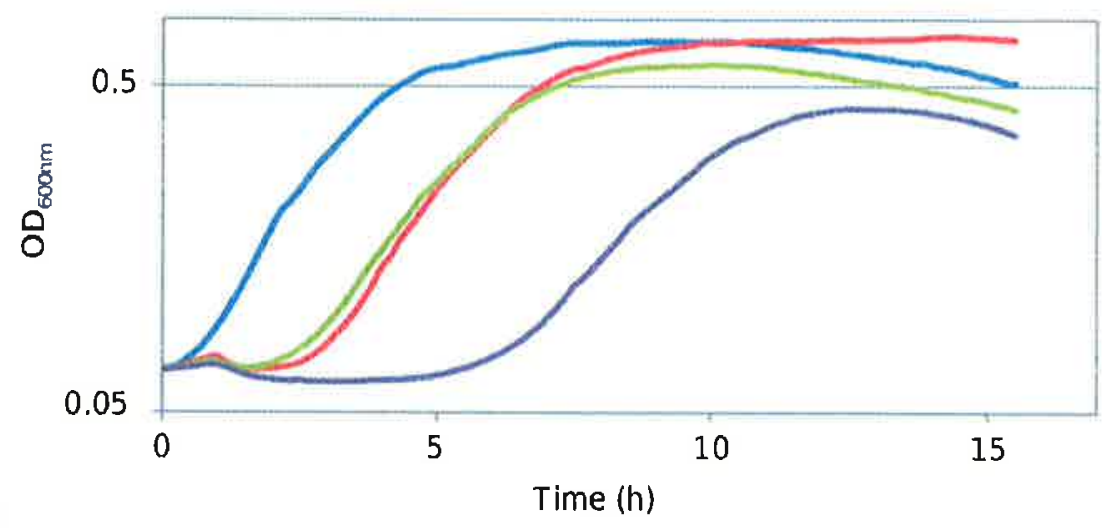

B

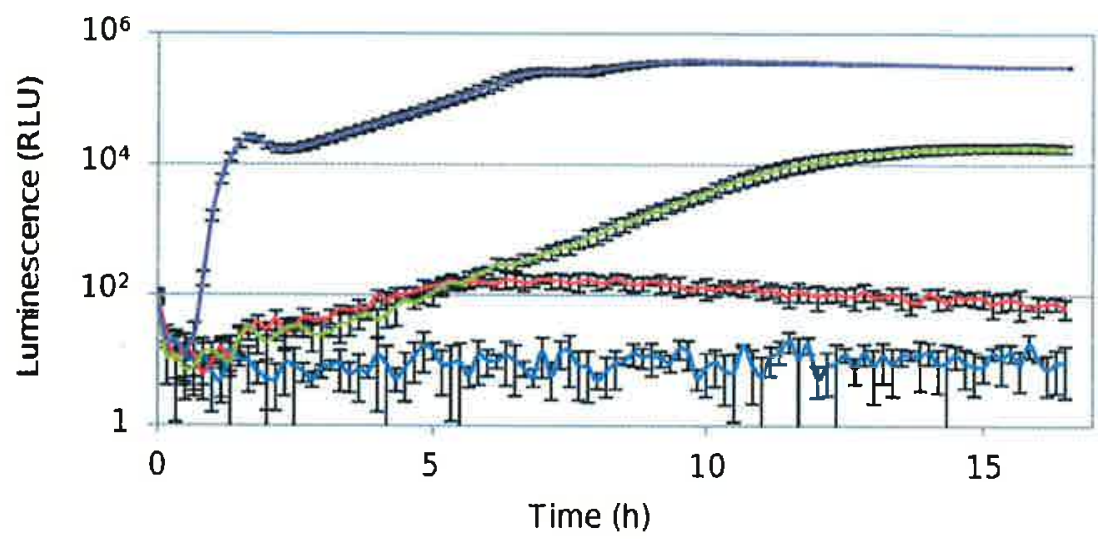

Figure 2. Luminescence emission upon infection with engineered HK620 phages. Bacterial growth (A) and luminescence profile (B) obtained from non infected E. coli TD2158 alone (blue), infected with WT HK620 (red) or recombinant phages HK620::PrpoD-luxCDABE (green), HK620::PrplU-luxCDABE (purple) were compared.

\section{Capsid structure of recombinant phages particles}

The insertion of the entire luxCDABE operon together with the PrplU promoter and a resistance cassette into the HK620 genome increased the genome size up to $120 \%$ compared to the WT HK620 genome. Considering the luminescence of the lysis plaques, each one arising from a single infecting recombinant phage, we obtained an homogenous population of recombinant phage (Fig. 3A). It thus looked that a vast majority of plaque forming units (pfu) integrated the whole construct. Several rounds of plaque isolation were performed to get an homogenous phage population. Therefore, we asked whether the packaging of large genome could modify the size and/or the shape of the capsid. We compared the perimeter and the sphericity of WT and recombinant HK620 capsids. Around hundred viral particles were analyzed using transmission electronic microscopy (see Material and Methods). Results show that recombinant phages 
had capsid with icosahedral structures as the WT HK620 phage (Fig. 3B). The capsid perimeters were $205 \pm$ $5 \mathrm{~nm}$ and $200 \pm 8 \mathrm{~nm}$ for HK620::Prp/U-luXCDABE and WT HK620, respectively (Fig. 3C). These results indicate that the recombination event did not affect the overall structure of the recombinant phages although an important add-on to the genome has been made. At this stage we did not know if the capsid of HK620 can tolerate such an increase in the genome size or if some dispensable parts of the genome are spontaneously deleted and/or rearranged as suggested in other phage engineering work (Springman et al., 2012). Only genome re-sequencing, which will be performed previous in field tests, will provide an answer.

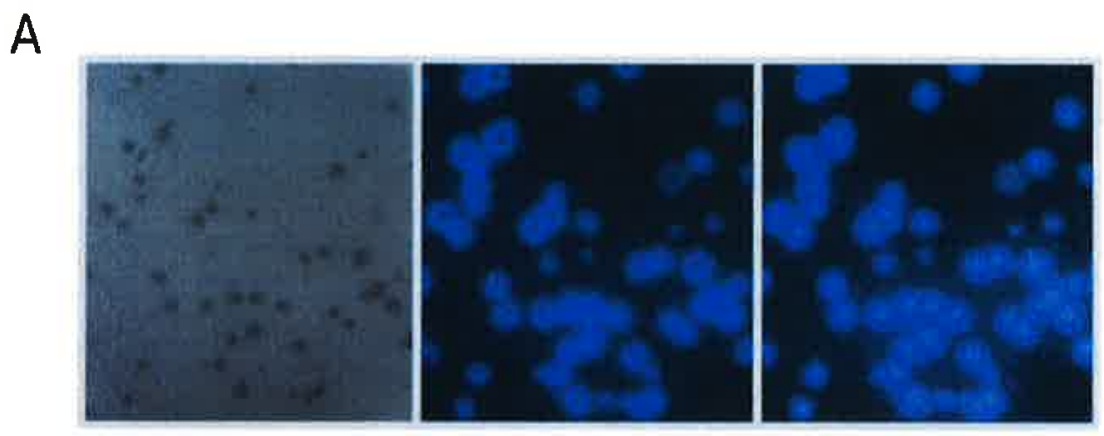

B

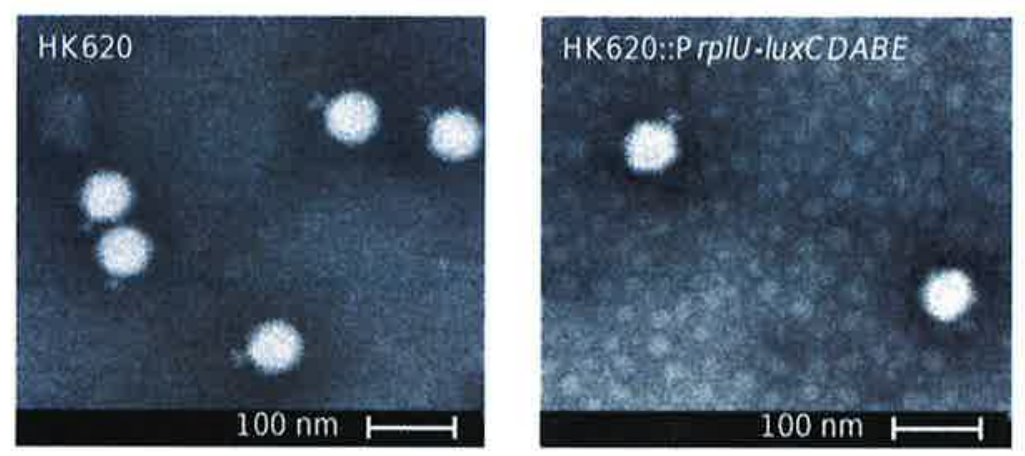

C

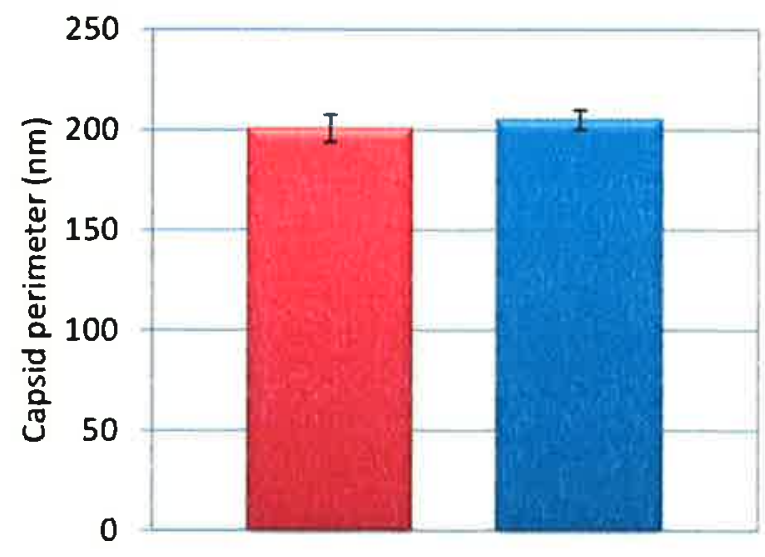

Figure 3. Characteristics of the HK620::PrpIU-IuxCDABE prototype. (A) Lysis plaques under white light (left), chemiluminescence emission (middle), and overlay (right); (B) Electron micrographs of WT HK620 (left) and HK620::Prp/U-luXCDABE (right); (C) Capsid perimeter average of WT HK620 (red) and HK620::Prp/U-luxCDABE (blue). $n$ $=100$. 


\section{Engineering of HK97 and $\lambda$ phage by insertion of lux operon}

Phage HK620 strictly infects the $E$. coli strain TD2158 (Dhillon et al., 1998). We used this phage-host couple to develop our prototypes. A general objective of the method is to develop phage-based biosensors with either non overlapping specificities, or with large recognition spectra to detect various strains at the same time. We thus attempted to engineer $E$. coli K12 infecting phages. HK97 and $\lambda$ phages specifically infect $E$. coli strains and use a cos system to package the DNA (Dhillon et al., 1980). The cos packaging system is described to be less flexible to variation in genome size than the pac packaging system (Campbell, 1994). In order to assess the impact of the insertion site on the stability of the engineered phage, we chose 2 intergenic regions devoid of transcription signals in HK97 and $\lambda$ genomes as insertion sites (Fig. 1). One region consists of the intergenic region between two convergent genes $r z$ and bor in $\lambda$ genome, the other one corresponds to the region downstream gene p56 in HK97. Briefly, we inserted easily the Prp/UluxCDABE operon into the genome of these prophages (i.e. under a genome-integrated form) using the $\lambda$ Red recombineering technique (Fig. 1 and Material and Methods section). The insertion generated an increase in genome size of $20 \%$ for $\mathrm{HK} 97$ and $16 \%$ for $\lambda$, whose genome sizes are $39 \mathrm{~kb}$ an $48 \mathrm{~kb}$, respectively. MMC treatment allowed the production and release of HK97::Prp/U-luXCDABE particles, and after 2 rounds of plaque purification, an homogenously luminescent population could be obtained (Fig. 4). In contrast, although the genetic construction was easily obtained, no viable $\lambda:$ PrplU-luxCDABE phage particle could be produced. These results indicate that although the cos system is known to be less tolerant than the pac one, it is not the only determinant that drives the success of large insertion engineering.

A

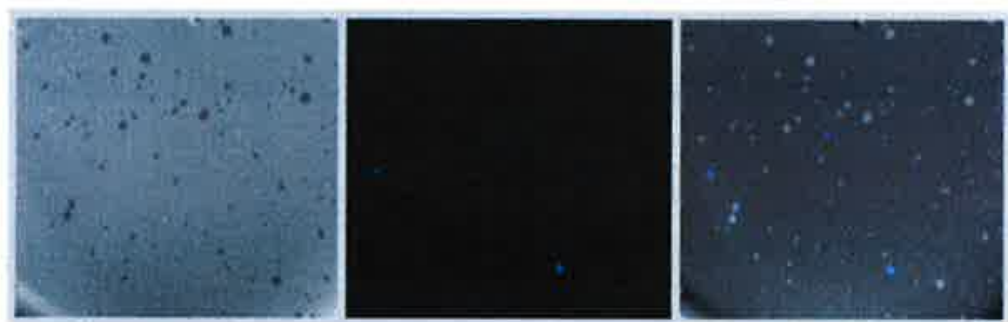

B

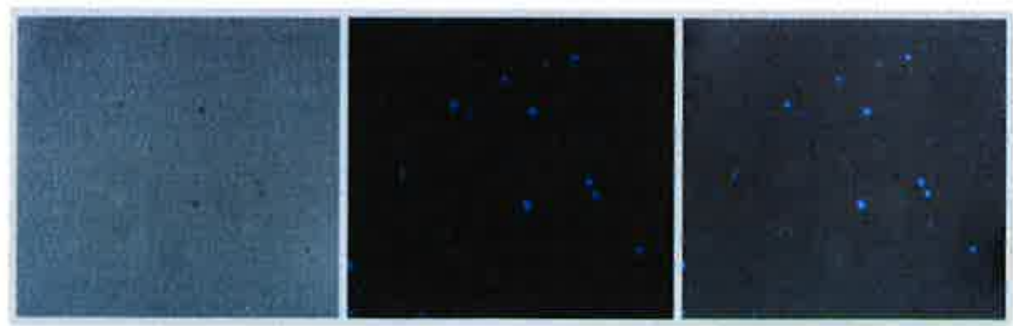

Figure 4. Enrichment of luminescent HK97::PrpIU-luxCDABE plaques (A) and (B) Lysis plaques under white light (left), chemiluminescence emission (middle), and overlay (right); (A) plaques obtained immediately post-MMC induction; (B) plaques obtained after two isolation rounds. 
We then analyzed the luminescence emission profiles obtained from non infected E. coli MG1655, infected with WT HK97 or recombinant phage HK97::PrplU-IUXCDABE (Fig. 5A). When E. coli MG1655 was infected with the WT phage, the luminescence signal was homogenous and did not differ significantly from what observed under non-infected conditions. In contrast, the luminescence rapidly increased during the first hour of infection and reached a maximum around 10 hours post-infection with HK97::Prp/U-IUXCDABE. When comparing the luminescence obtained post-infection in strains MG1655 and TD2158, using two different phages nonetheless carrying the same reporter fusion, we found that the signal was higher in strain TD2158, indicating that the genetic background influences the emission of chemiluminescence (Fig. 5B, light curves), regardless of the CFU/mi present in the assay (data not shown). Moreover, we found that the background level of luminescence was higher in MG1655 than in TD2158 (Fig. 5B, dark curves). Therefore, considering these two strains, the ratio signal over noise is very different from one strain to another, and this aspect will have to be taken into consideration for future developments.

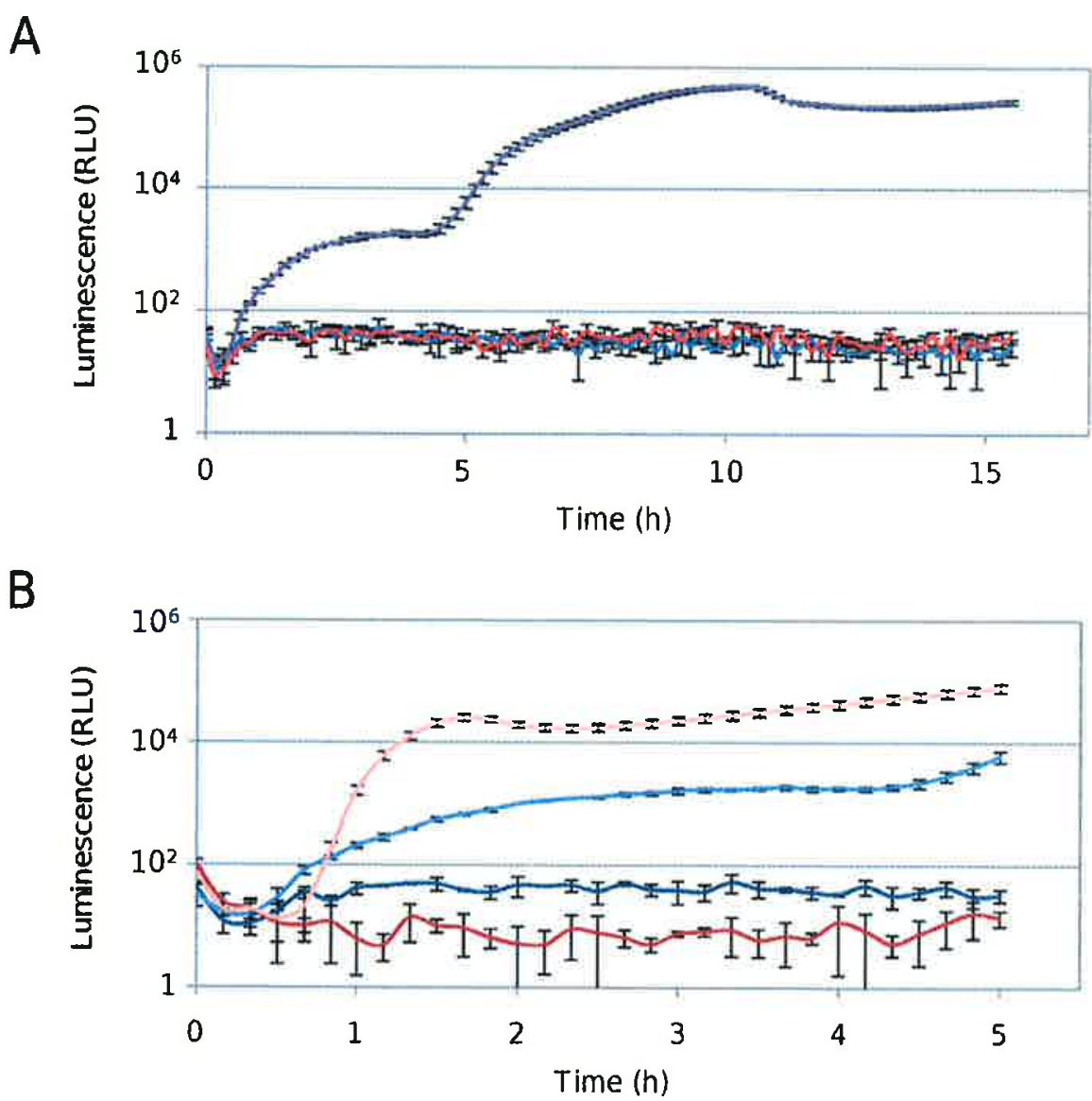

Figure 5. (A) Luminescence profile obtained from non infected E. coli MG1655 alone (blue), infected with WT HK97 (red) or recombinant phage HK97::Prp/U-/UXCDABE (purple) were compared. (B) Luminescence profile obtained from MG1655 (blue) and TD2158 (red) alone (dark curves) or infected with recombinant phages HK620::Prp/U-luxCDABE or HK97::Prp/U-luxCDABE respectively (light curves) were compared for 5 hours. 


\section{Detection limit}

In order to reach the limit of detection, samples at a concentration of $10^{7}$ bacteria. $\mathrm{ml}^{-1}$ were serially 10 -fold diluted in supplemented M9 medium before infection with HK620::Prp/U-luxCDABE. The luminescence intensity was monitored every $10 \mathrm{~min}$ for 2 hours. The results illustrated in Fig. 6A indicated that the signal generated 1.5 hours post-infection and after on, in a sample containing $E$. coli TD2158 cells at a concentration of $10^{4}$ bacteria. $\mathrm{ml}^{-1}$ is higher than the basal luminescence. Therefore, we show that detection of bacteria is possible using this tool. It is important to notice that the linearity of the detection is not affected by the $\mathrm{MOI}$ since in this assay the $\mathrm{MOI}$ varies according to the density of the bacterial suspension. We also tested the detection of $E$. coli TD2158 cells present in a tap water sample artificially contaminated (Fig. 6B). An overnight bacterial culture was centrifuged and cells were resuspended in tap water. The artificially contaminated sample was incubated at room temperature overnight to mimic an accidental contamination. The spiked sample was serially 10 -fold diluted in tap water then each bacterial sample was infected with HK620::PrplU-luXCDABE. The limit of detection obtained with HK620::Prp/U-luXCDABE in tap water was around $10^{4}$ bacteria. $\mathrm{ml}^{-1}$. Thus, the sensitivity in tap water is comparable to what obtained in supplemented M9 medium. 

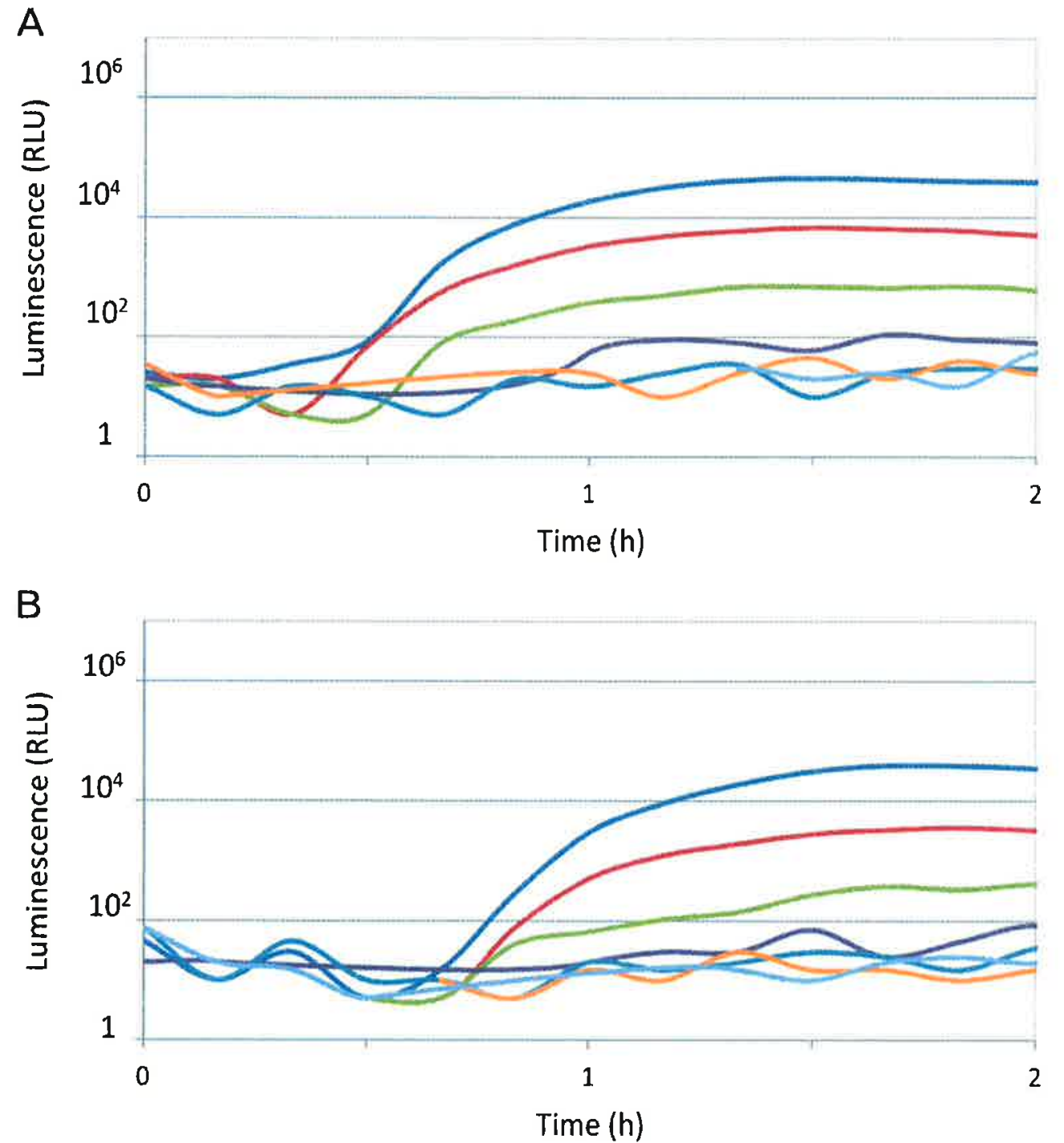

Fig. 6 Assay limits. (A) Determination of the minimal concentration of E. coli TD2158 that can be detected. Serial 10 fold dilutions ranging from $10^{7}$ to $10^{1}$ bacteria. $\left.\right|^{-1}$ were infected with HK620::PrplU-luxCDABE phage. Infected cells were incubated at $30^{\circ} \mathrm{C}$. Luminescence was monitored each $10 \mathrm{~min}$ using a microplate reader. (B) Detection in a spiked tap water sample. $E$. coli TD2158 in stationary phase was added to a tap water sample. After an overnight incubation at room temperature, the sample was infected with HK620::Prp/U-luxCDABE. Luminescence intensity was monitored every $10 \mathrm{~min}$. Color code: $10^{7}$ bacteria. $\mathrm{m}^{-1}=$ dark blue $\left(\mathrm{MOI}=10^{1}\right), 10^{6}=\operatorname{red}\left(\mathrm{MOI}=10^{2}\right), 10^{5}=$ green $\left(\mathrm{MOI}=10^{3}\right), 10^{4}=$ purple $\left(\mathrm{MOI}=10^{4}\right), 10^{3}=$ turquoise $\left(\mathrm{MOI}=10^{5}\right), 10^{2}=$ orange $\left(\mathrm{MOl}=10^{6}\right), 10^{1}=$ light blue $\left(\mathrm{MOI}=10^{7}\right)$.

\section{Materials and Methods}

\section{Bacterial strains, bacteriophages and media used in this study}

Bacterial strains and bacteriophages used in this study are listed in Table 1. The presence of the HK620, $\lambda$ and HK97 prophages in strains TD2158 and MG1655 was checked by PCR amplification of the att sites using dedicated primer pairs (Table 2). When necessary ampicillin $\left(100 \mu \mathrm{g} \cdot \mathrm{ml}^{-1}\right)$ or kanamycin $\left(40 \mu \mathrm{g} \cdot \mathrm{ml}^{-1}\right)$ were 
added to growth media. LB medium was used for lysogen growth and infections. When necessary, $1.5 \%$ (hard) or $0.75 \%$ (soft) of agar was added to the growth medium. M9 minimal medium supplemented with casamino acids $(0.2 \%)$, D-glucose $(0.3 \%)$, vitamin $\mathrm{B} 1\left(1 \mathrm{mg} \cdot \mathrm{ml}^{-1}\right), \mathrm{MgSO}_{4}(0.2 \mathrm{mM}), \mathrm{CaCl}_{2}(0.1 \mathrm{mM})$ was used for luminescence detection assays.

\section{Phage engineering}

Recombinant prophages were constructed by the insertion of luxCDABE (Gene bank accession number: M90093.1) and kanamycin resistance genes into intergenic regions of HK620, $\lambda$ and HK97 prophages using the lambda Red homologous recombination method (Datsenko and Wanner, 2000). PCR fragments used as substrates for homologous recombination are described in Fig 1. They contain the luxCDABE operon under the control of either PrplU or PrpoD promoters and the kanamycin resistance-cassette, flanked by $80 \mathrm{bp}$ of homology with the integration region. To construct the PrplU-luxCDABE plasmid, the PrpoD promoter of plasmid PrpoD-luxCDABE (Preveral, S. et al., in this issue) was exchanged with the PrplU promoter using EcoRI and Ncol sites. PCRs were performed using the high fidelity DNA polymerase PrimeSTAR Max Premix 2X (Takara), plasmids PrpoD-luxCDABE, PrplU-luxCDABE (1 ng. $\mathrm{ll}^{-1}$ ) as templates and primer pairs listed in Table 2. PCR fragments purified using the QIAquick PCR purification Kit (Qiagen) were treated with the restriction enzyme Dpnl (Takara) in order to eliminate the template plasmids. After a purification step using the MinElute reaction cleanup kit (Qiagen), $1.5 \mu \mathrm{g}$ of PCR fragments were electroporated into LCB6205(HK620)/pKD46, MG1655(入)/pKD46 and MG1655(HK97)/pKD46 using the Eporator electroporation system (Eppendorf). Luminescent colonies were selected with a luminescence imager (LAS4000, GE Healthcare). The integration of the constructs was checked by PCR using flanking primers. Two isolation rounds were performed to select for recombinant lysogenic bacteria only.

\section{MMC induction, production and purification of recombinant phages}

Recombinant phages were collected following MMC induction $\left(5 \mu \mathrm{g} \cdot \mathrm{ml}^{-1}\right)$ under shaking for 3 hours. Then, cells were treated twice with chloroform and peleted by centrifugation at $4,500 \mathrm{~g}$ for $10 \mathrm{~min}$, the supernatants were filtered $(0.22 \mu \mathrm{m})$ and stocked at $4^{\circ} \mathrm{C}$. For phage production, $100 \mu \mathrm{l}$ of phage suspension (around $10^{9} \mathrm{PFU} . \mathrm{ml}^{-1}$ ) and $100 \mu \mathrm{l}$ of an overnight host culture were mixed with $3 \mathrm{ml}$ of LB soft agar and spread onto a LB plate. After incubation overnight at $37^{\circ} \mathrm{C}$, the top agar layer was collected and mixed with $10 \mathrm{ml}$ of LB. The mix was left standing for $30 \mathrm{~min}$ to allow phage diffusion into the medium and treated twice with chloroform as described above. Phages were then purified by centrifugation at 20,000 g for 1 hour. Phage pellets were resuspended in Tris- $\mathrm{HCl} 50 \mathrm{mM} \mathrm{pH}$ 8.0, NaCl $100 \mathrm{mM}$, buffer and incubated overnight at $4^{\circ} \mathrm{C}$ under shaking. Purified phage suspensions were titered and kept at $4^{\circ} \mathrm{C}$. To reach homogeneity in the engineered phage population several round of plaque isolation were sometimes necessary. Briefly, instead of recovering the entire soft agar layer, individual plaques were recovered and 
isolated on a new soft agar plate. Lysis plaques were then observed to check the luminescence of individual plaques.

\section{Optical density and luminescence measurements post-infection}

To monitor growth of the bacteria upon infection, the $\mathrm{OD}_{600}$ was measured as a function of time. An overnight culture was diluted at a initial $O D_{600}$ of 0.1 in $1 \mathrm{ml}$ of $L B$ medium and the appropriate volume of phage suspension was added to reach a multiplicity of infection (MOI) of $10.170 \mu \mathrm{l}$ of the mixture were added to a microplate with clear bottom (CELSTAR ${ }^{\oplus}, 96$ well Microplate, White $/ \mu$ Clear ${ }^{\oplus}$, Greiner bio one) and incubated at $30^{\circ} \mathrm{C}$ without agitation. $\mathrm{OD}_{600}$ was measured every 10 minutes for 12 hours. Luminescence monitoring was performed the same way except that white microplates were used (CELLSTAR ${ }^{\varpi}, 96$ well Microplate, all White, Greiner bio one). Luminescence was monitored using the Infinite ${ }^{\circledR}$ M200 (Tecan) system. For the determination of the limits of detection, experiments were carried out in supplemented M9 medium and we used a single concentration of phage added to the diluted bacterial suspension, therefore the $\mathrm{MOI}$ varied according to the density of the bacterial suspension.

\section{Electronic microscopy}

Electronic microscopy was performed at the Mediterranean Institute of Microbiology (IMM) facility. Phage suspensions $(5 \mu \mathrm{l})$ were dropped onto a copper grid covered with Formvar and carbon and left $3 \mathrm{~min}$. at 25 ${ }^{\circ} \mathrm{C}$, after what the excess of liquid was removed. Phage particles were stained according to (Ackermann, 2009 ) with a $2 \%$ uranyl acetate solution. Dried grids were then observed using a transmission microscope FEI Tecnai $200 \mathrm{kV}$ coupled to a Eagle CCS $2 \mathrm{k} \times 2 \mathrm{k}$ camera. Images were then analyzed using the Image software.

\section{Conclusions}

The major requirement of the COMBITOX project was to adapt our biodetection system based on bacteriophage engineering to luminescence detection (Ansaldi et al., 2015). In order to design a substrate independent biodetector, we used as a reporter system the entire luxCDABE operon that encodes a luciferase as well as the substrate generating system. The engineering step, although very challenging given the small size of bacteriophage genomes, was successful since we managed to engineer two functional phages HK62O and HK97 that have different packaging systems and without removing any part of the respective phage genomes. Our results indicate that lux phages could be used to detect around $10^{4}$ bacteria/ml, which is only two log apart from the limit imposed by the EU regulation (European directive 2006/7/EC of the European Parliament and of the Council of 15 february 2006 concerning the management of bathing water quality and repealing Directive 76/160/EEC). Further improvements, in particular a luminescence detection device with a higher sensitivity, such as developed in (Descamps, E. et al., in this 
issue) are needed to reach the European guidelines. The design and development of substrate independent phage-based biosensors will be pursued in order to detect Enterobacteriacae strains commonly found as pollutants in water distribution networks. A key issue will be to detect enteric bacteria after a prolonged stay in water. Indeed, upon an accidental human or animal contamination, most bacteria present in the environment are in a stationary phase or are considered as viable but not cultivable (VBNC) (Li et al., 2014). In a previous work, we showed that $g f p$ versions of our prototypes were suitable to detect $E$. coli cells incubated $24 \mathrm{~h}$ in sea water (Vinay et al., 2015). Once the luminescence detection will be improved to match the regulation, appropriate assays will be performed with the luminescent versions of the phagebased biosensors to detect bacteria under prolonged stationary phase condition or VBNC bacteria.

\section{Acknowledgments}

We thank all members of the phage lab' and the COMBITOX consortium for stimulating discussions. We are grateful to Artemis Costa (Electronic microscopy facility), Leon Espinosa for help with microscopy and data analysis, and to Marie-Agnès Petit for sending the HK97 lysogen. 


\section{References}

Ackermann, H.-W. (2009). Basic phage electron microscopy. Methods Mol. Biol. Clifton NJ 501, 113-126.

Ansaldi, M., Bazin, I., Cholat, P., Rodrigue, A., and Pignol, D. (2015). Toward inline multiplex biodetection of metals, bacteria, and toxins in water networks: the COMBITOX project. Environ. Sci. Pollut. Res. Int.

Blattner, F.R., Plunkett, G., Bloch, C.A., Perna, N.T., Burland, V., Riley, M., Collado-Vides, J., Glasner, J.D., Rode, C.K., Mayhew, G.F., et al. (1997). The complete genome sequence of Escherichia coli K-12. Science $277,1453-1474$.

Byappanahalli, M.N., Nevers, M.B., Korajkic, A., Staley, Z.R., and Harwood, V.J. (2012). Enterococci in the environment. Microbiol. Mol. Biol. Rev. MMBR 76, 685-706.

Campbell, A. (1994). Comparative Molecular Biology of Lambdoid Phages. Annu. Rev. Microbiol. 48, 193222.

Clark, A.J., Inwood, W., Cloutier, T., and Dhillon, T.S. (2001). Nucleotide sequence of coliphage HK620 and the evolution of lambdoid phages. J.Mol.Biol. 311, 657-679.

Datsenko, K.A., and Wanner, B.L. (2000). One-step inactivation of chromosomal genes in Escherichia coli K12 using PCR products. Proc Natl Acad Sci U A 97, 6640-6645.

Derda, R., Lockett, M.R., Tang, S.K.Y., Fuller, R.C., Maxwell, E.J., Breiten, B., Cuddemi, C.A., Ozdogan, A., and Whitesides, G.M. (2013). Filter-Based Assay for Escherichia coli in Aqueous Samples Using BacteriophageBased Amplification. Anal. Chem. 85, 7213-7220.

Descamps, E., Franche, Nathalie, Meunier, D., Miclot, B., Larosa, P., Brutesco, C., Garcia, D., Bazin, I., Pignol, D., Cholat, P., et al. (in this issue). Semi-autonomous inline water analyzer: design of a common light detector for bacterial, phage and immunological biosensors.

D'Herelle, F. (2007). On an invisible microbe antagonistic toward dysenteric bacilli: brief note by Mr. F. D'Herelle, presented by Mr. Roux. 1917. Res. Microbiol. 158, 553-554.

Dhillon, E.K., Dhillon, T.S., Lai, A.N., and Linn, S. (1980). Host range, immunity and antigenic properties of lambdoid coliphage HK97. J. Gen. Virol. 50, 217-220.

Dhillon, T.S., Poon, A.P., Chan, D., and Clark, A.J. (1998). General transducing phages like Salmonella phage P22 isolated using a smooth strain of Escherichia coli as host. FEMS MicrobiolLett 161, 129-133.

Edberg, S.C., Rice, E.W., Karlin, R.J., and Allen, M.J. (2000). Escherichia coli: the best biological drinking water indicator for public health protection. Symp. Ser. Soc. Appl. Microbiol. 106S - 1165.

Edgar, R. (2006). High-sensitivity bacterial detection using biotin-tagged phage and quantum-dot nanocomplexes. Proc. Natl. Acad. Sci. 103, 4841-4845.

Goodridge, L., and Abedon, S.T. (2003). Bacteriophage biocontrol and bioprocessing: Application of phage therapy to industry. SIM News 53, 254-262.

Haq, I.U., Chaudhry, W.N., Akhtar, M.N., Andleeb, S., and Qadri, I. (2012). Bacteriophages and their Implications on Future Biotechnology: A Review. Virol. J. 9, 9.

Hendrix, R, Roberts, J.W., Stahl, F.W., and Weisberg, R.A. (1983). Lambda II (Cold Spring Harbor Laboratory Press). 
Juhala, R.J., Ford, M.E., Duda, R.L., Youlton, A., Hatfull, G.F., and Hendrix, R.W. (2000). Genomic sequences of bacteriophages HK97 and HKO22: pervasive genetic mosaicism in the lambdoid bacteriophages. J. Mol. Biol. 299, 27-51.

Kim, S., Kim, M., and Ryu, S. (2014). Development of an engineered bioluminescent reporter phage for the sensitive detection of viable Salmonella Typhimurium. Anal. Chem. 86, 5858-5864.

Kuhn, J.C. (2007). Detection of Salmonella by bacteriophage Felix 01. Methods Mol. Biol. Clifton NJ 394, 2137.

Li, L., Mendis, N., Trigui, H., Oliver, J.D., and Faucher, S.P. (2014). The importance of the viable but nonculturable state in human bacterial pathogens. Front. Microbiol. 5.

Loessner, M.J., Rees, C.E., Stewart, G.S., and Scherer, S. (1996). Construction of luciferase reporter bacteriophage $A 511:$ :luxAB for rapid and sensitive detection of viable Listeria cells. Appl. Environ. Microbiol. 62, 1133-1140.

Menouni, R., Champ, S., Espinosa, L., Boudvillain, M., and Ansaldi, M. (2013). Transcription termination controls prophage maintenance in Escherichia coli genomes. Proc. Natl. Acad. Sci. U. S. A. 110, 1441414419.

Mosier-Boss, P.A., Lieberman, S.H., Andrews, J.M., Rohwer, F.L., Wegley, L.E., and Breitbart, M. (2003). Use of fluorescently labeled phage in the detection and identification of bacterial species. Appl. Spectrosc. 57, 1138-1144.

Panis, G., Duverger, Y., Champ, S., and Ansaldi, M. (2010). Protein binding sites involved in the assembly of the KplE1 prophage intasome. Virology 404, 41-50.

Piuri, M., Jacobs, W.R., and Hatfull, G.F. (2009). Fluoromycobacteriophages for Rapid, Specific, and Sensitive Antibiotic Susceptibility Testing of Mycobacterium tuberculosis. PLOS ONE 4, e4870.

Pond, K., and World Health Organization (2005). Water recreation and disease plausibility of associated infections: acute effects, sequelae, and mortality (London; Seattle: Published on behalf of the World Health Organization by IWA Pub.).

Prévéral, S., Brutesco, C., Descamps, E.C.T., Escoffier, C., Pignol, D., Ginet, N., and Garcia, D. (2016). A bioluminescent arsenite biosensor designed for inline water analyzer. Environ. Sci. Pollut. Res. Int.

Preveral, S., Brutesco, C., Descamps, E., Escoffier, C., Ginet, N., Pignol, D., and Garcia, D (in this issue). A bioluminescent arsenite biosensor designed for inline water analyzer.

Schmelcher, M., and Loessner, M.J. (2014). Application of bacteriophages for detection of foodborne pathogens. Bacteriophage 4, e28137.

Schofield, D.A., Molineux, I.J., and Westwater, C. (2009). Diagnostic bioluminescent phage for detection of Yersinia pestis. J. Clin. Microbiol. 47, 3887-3894.

Springman, R., Molineux, I.J., Duong, C., Bull, R.J., and Bull, J.J. (2012). Evolutionary stability of a refactored phage genome. ACS Synth. Biol. 1, 425-430.

Stewart, J.R., Gast, R.J., Fujioka, R.S., Solo-Gabriele, H.M., Meschke, J.S., Amaral-Zettler, L.A., del Castillo, E., Polz, M.F., Collier, T.K., Strom, M.S., et al. (2008). The coastal environment and human health: microbial indicators, pathogens, sentinels and reservoirs. Environ. Health 7, S3. 
Toranzo, A.E., Magariños, B., and Romalde, J.L. (2005). A review of the main bacterial fish diseases in mariculture systems. Aquaculture 246, 37-61.

Twort, F.W. (1915). An investigation on the nature of ultra-microscopic viruses. The Lancet 186, 1241-1243.

Vinay, M., Franche, N., Grégori, G., Fantino, J.-R., Pouillot, F., and Ansaldi, M. (2015). Phage-Based Fluorescent Biosensor Prototypes to Specifically Detect Enteric Bacteria Such as E. coli and Salmonella enterica Typhimurium. PLoS ONE 10, e0131466.

Waddell, T.E., and Poppe, C. (2000). Construction of mini-Tn10luxABcam/Ptac-ATS and its use for developing a bacteriophage that transduces bioluminescence to Escherichia coli 0157:H7. FEMS Microbiol. Lett. 182, 285-289.

Zaslaver, A., Bren, A., Ronen, M., Itzkovitz, S., Kikoin, I., Shavit, S., Liebermeister, W., Surette, M.G., and Alon, U. (2006). A comprehensive library of fluorescent transcriptional reporters for Escherichia coli. Nat.Methods 3, 623-628. 
1

3

4

5

6

9

10

11

12

13

14

15

16

17

18

19

20

21

22

24

25

29

30

31

34

35

36

37

38

39 
Table 1. E. coli strains and bacteriophages used in this study

\begin{tabular}{|c|c|c|}
\hline Strains & Characteristics & References \\
\hline TD2158 & Environmental Escherichia coli $\mathrm{H}$ strain & (Dhillon et al., 1998) \\
\hline LCB6205 & $\begin{array}{l}\text { Phage-free Escherichia coli TD2158, previously } \\
\text { named } E \text {. coli TD2158_PL4 }\end{array}$ & (Menouni et al., 2013) \\
\hline LCB6205(HK620) & LCB6205 lysogen for HK620 & (Vinay et al., 2015) \\
\hline LCB6146 & LCB6205(HK620 hkcEF::PrpoD-luxCDABE), $\mathrm{Km}^{\mathrm{R}}$ & This work \\
\hline LCB6147 & LCB6205(HK620 hkcEF::PrplU-luxCDABE), $\mathrm{Km}^{\mathrm{R}}$ & This work \\
\hline MG1655 & Reference Escherichia coli K12 strain & (Blattner et al., 1997) \\
\hline MG1655(HK97) & MG1655 lysogen for HK97 & M.A. Petit \\
\hline LCB6188 & 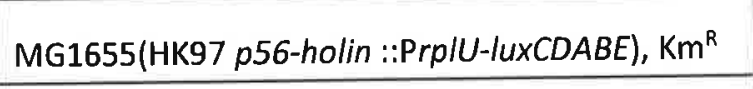 & This work \\
\hline $\operatorname{MG1655}(\lambda)$ & MG1655 lysogen for $\lambda$ & Lab' collection \\
\hline Bacteriophages & & \\
\hline HК620 & $\begin{array}{l}\text { Temperate bacteriophage specifically infects } E \text {. } \\
\text { coli TD } 2158\end{array}$ & $\begin{array}{l}\text { (Clark et al., 2001; } \\
\text { Dhillon et al., 1998) }\end{array}$ \\
\hline $\begin{array}{l}\text { HK620 hkcEF::PrpoD- } \\
\text { luxCDABE }\end{array}$ & Recombinant phage induced from LCB6146 & This work \\
\hline $\begin{array}{l}\text { HK620 hkcEF::PrplU- } \\
\text { luxCDABE }\end{array}$ & Recombinant phage induced from LCB6147 & This work \\
\hline$\lambda$ & Temperate bacteriophage, infects $E$. coli $\mathrm{K} 12$ & (Hendrix, R et al., 1983) \\
\hline HK97 & Temperate bacteriophage, infects $E$. coli $\mathrm{K} 12$ & (Juhala et al., 2000) \\
\hline $\begin{array}{l}\text { HK97 p56-holin } \\
\text { ::PrplU-luxCDABE }\end{array}$ & Recombinant phage induced from LCB6188 & This work \\
\hline
\end{tabular}


Table 2. Plasmids and primers used in this study

\begin{tabular}{|c|c|c|}
\hline Plasmids & Characteristics & References \\
\hline pKD46 & $\begin{array}{l}\text { lambda Red expression plasmid. bla, araC, } \\
\text { gam, bet, exo genes; Pbad promoter; ori R101 }\end{array}$ & $\begin{array}{l}\text { (Datsenko and Wanner, } \\
2000 \text { ) }\end{array}$ \\
\hline PrplU-gfp & pUA139 containing the PrplU promoter region & E. Bouveret \\
\hline PrpoD-IUXCDABE & p15A origin, kan $^{R}$ & (Prévéral et al., 2016) \\
\hline PrplU-luxCDABE & & This work \\
\hline Primers & Sequences $^{\mathrm{a}}$ & References \\
\hline pRplU-EcoRI-Rev & CGGAATTCGTGTCCAGCTITCCAGGC & \\
\hline Ncol-pUA66-Fow & CAATCCATGGGAGGCCCTTCGTCTTCAC & \\
\hline attL-ter & CATCGAGAAGGCGGTATGGTIITTC & (Panis et al., 2010) \\
\hline attL-pro & AATGGATATAACGAGCCCCTCC & (Panis et al., 2010) \\
\hline attL-Lambda-Fwd & ACCAGGCGCGGTITGATCAG & \\
\hline attL-Lambda-Int-Rev & TTCACGAGTTGCGCAGTITG & \\
\hline attR-Lambda-Rev & GCGCAATGCCATCTGGTATC & \\
\hline pRpoDlux_hkcEF_Fow & $\begin{array}{l}\text { GTTCAGTTAGTGTGAGGTTGATGCTGCAGCGTCA } \\
\text { GGTGTGAGTATTTGATATCTACGAAATAATGTGC } \\
\text { TITGCATAATTTCCATGGGCATACTTGATGA } \\
\end{array}$ & \\
\hline pRpoDlux_hkcEF_Rev & $\begin{array}{l}\text { AATATCAATTACATCTTTCTGTITATGGTGTGAC } \\
\text { CATTACATGCTITATATAAACAATTCTTCTTGGT } \\
\text { TIATCATGTATCAACAAAGCCACGTTGTGT } \\
\end{array}$ & \\
\hline pUA66_hkcEF_Fow & $\begin{array}{l}\text { GTTCAGTTAGTGTGAGGTTGATGCTGCAGCGTCA } \\
\text { GGTGTGAGTATTGATATCTACGAAATAATGTGC } \\
\text { TITGCATAATTGGAGGCCCTTTCGTCTTCAC }\end{array}$ & \\
\hline hkcE_dir & TTGGTTGGGGTTGGGTATAA & (Vinay et al., 2015) \\
\hline hkcE_down_rev & CACCACGAGGTGGTTAAAGC & (Vinay et al., 2015) \\
\hline pUA-Lambda-Rz-Bor-F & $\begin{array}{l}\text { AGAGGCTGATCACTATGCAAAAACAACTGGAAG } \\
\text { GAACCCAGAAGTATATTAATGAGCAGTGCAGAT } \\
\text { AGAGTTGCCCATATGGAGGCCCTTTCGTCTTCAC }\end{array}$ & \\
\hline pLUX-Lambda-RZ-Bor-R & $\begin{array}{l}\text { CGGTTTATTACTTIAGGCATTTATACTCCGCTGG } \\
\text { AAGCGCGTGTGTATTGCTCACAATAATTGCATGA } \\
\text { GTTGCCCATCGTCAACAAAGCCACGTTGTGT }\end{array}$ & \\
\hline pUA-HK097-p56-Holin-F & $\begin{array}{l}\text { GAAGAGTCAATTGCAGACAACATITGAACGCG } \\
\text { GTCACACGTTAGCAGCATGATTGCCACGGATGG } \\
\text { CAACATATTAACGGGGAGGCCCTTTCGTCTTCAC }\end{array}$ & \\
\hline pLUX-HK097-p56-Holin-R & $\begin{array}{l}\text { TCAGGGCTTTATITAACGAGTGCATTTATCCATCG } \\
\text { TTGATGTCAAATITACCCAACTTTATTCAAAAAGT } \\
\text { CAATATCATGTCAACAAAGCACGTTGTGTC }\end{array}$ & \\
\hline Bor-lambda-Rev & GGCAGCAGTAGCACCAAAGG & \\
\hline
\end{tabular}

a sequences in bold correspond to priming sequences that allow the amplification of the PCR fragments used for recombination. 


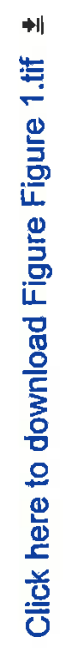

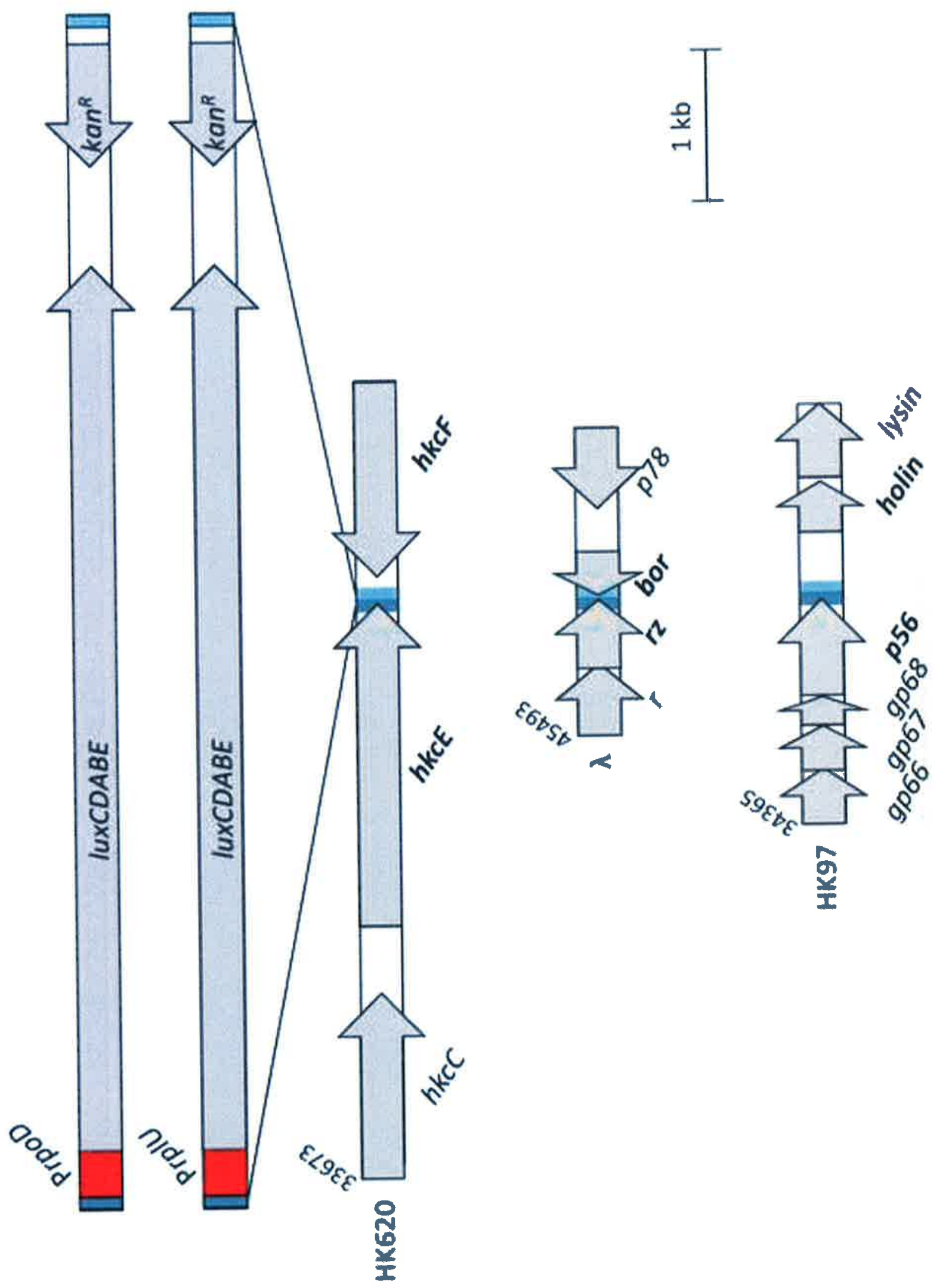

這 
A
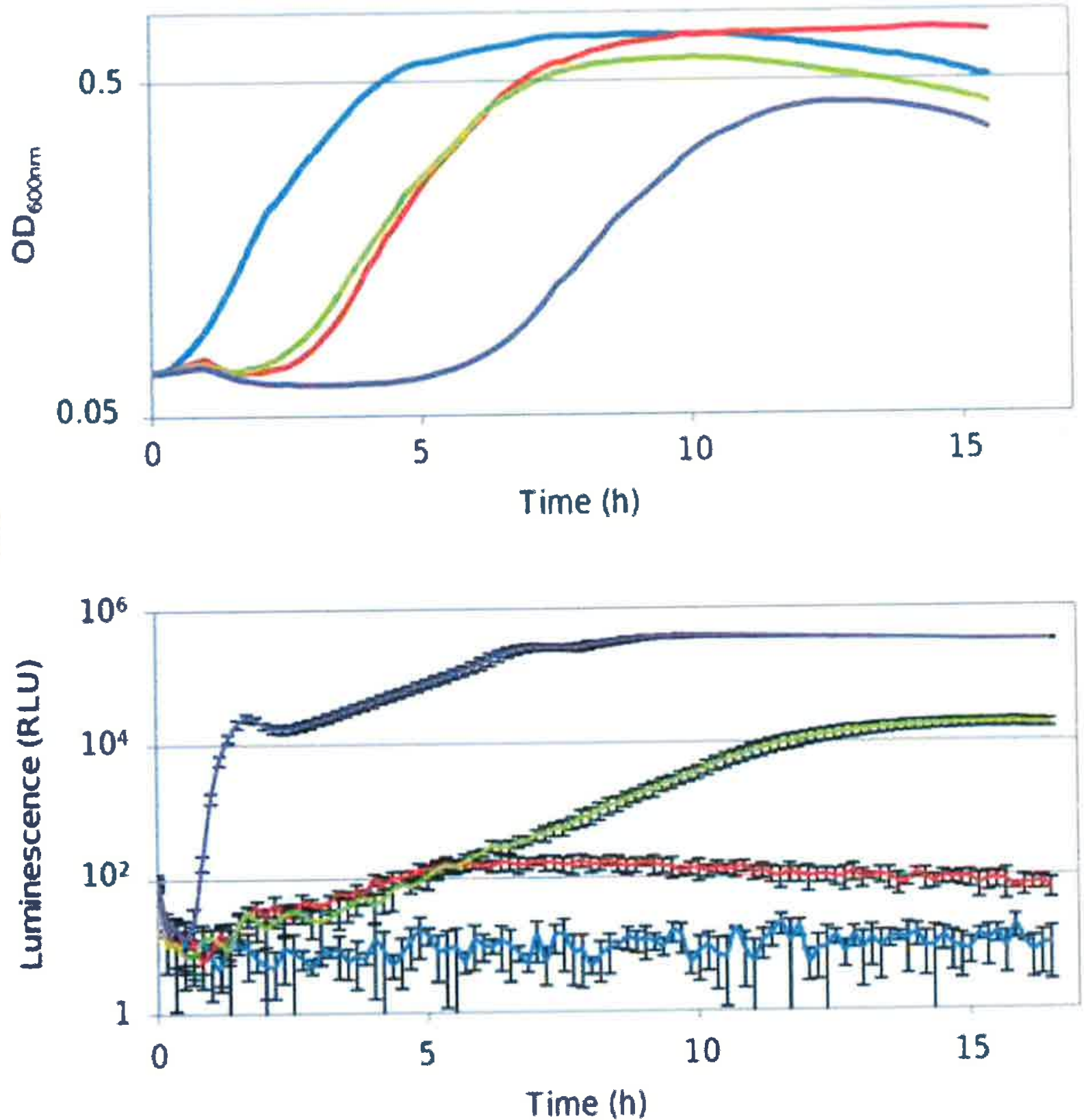


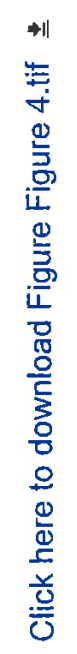
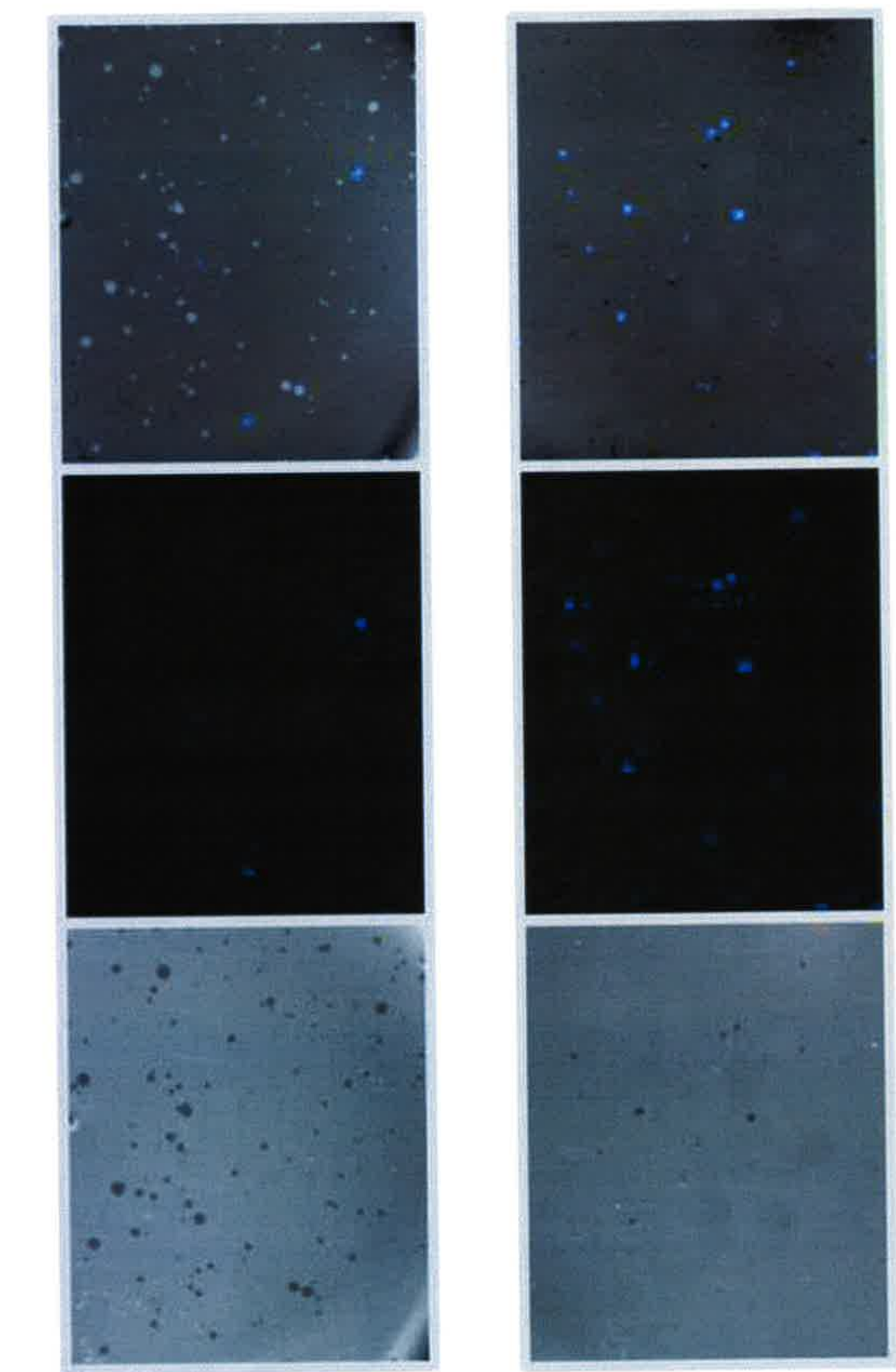

$\varangle$

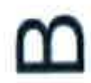

选 
A
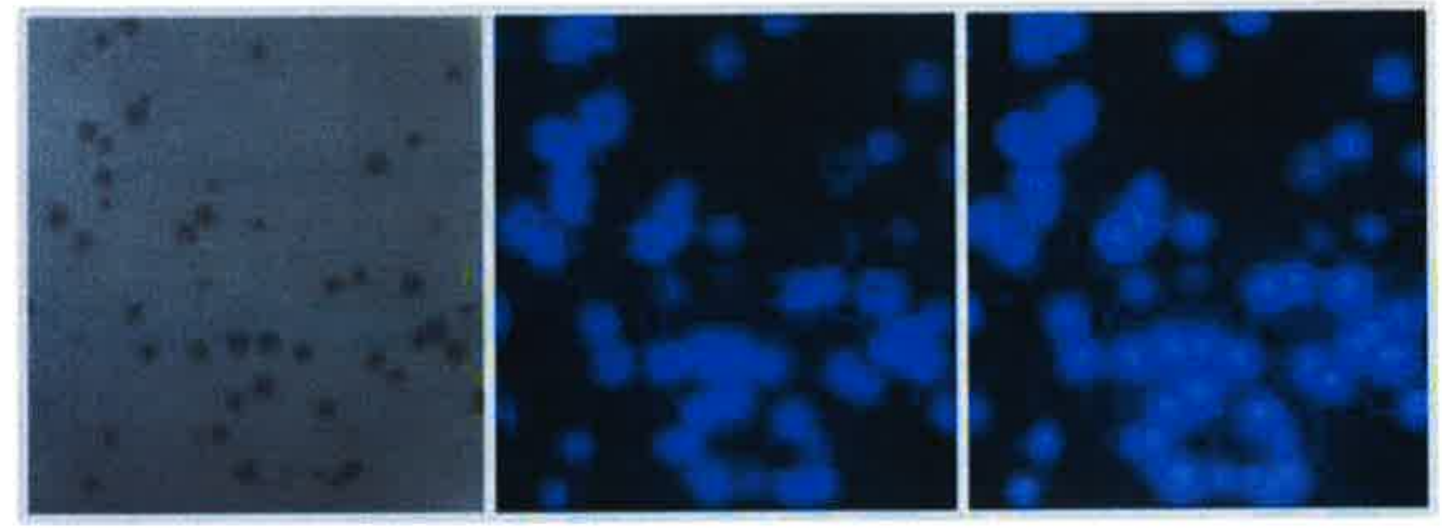

B
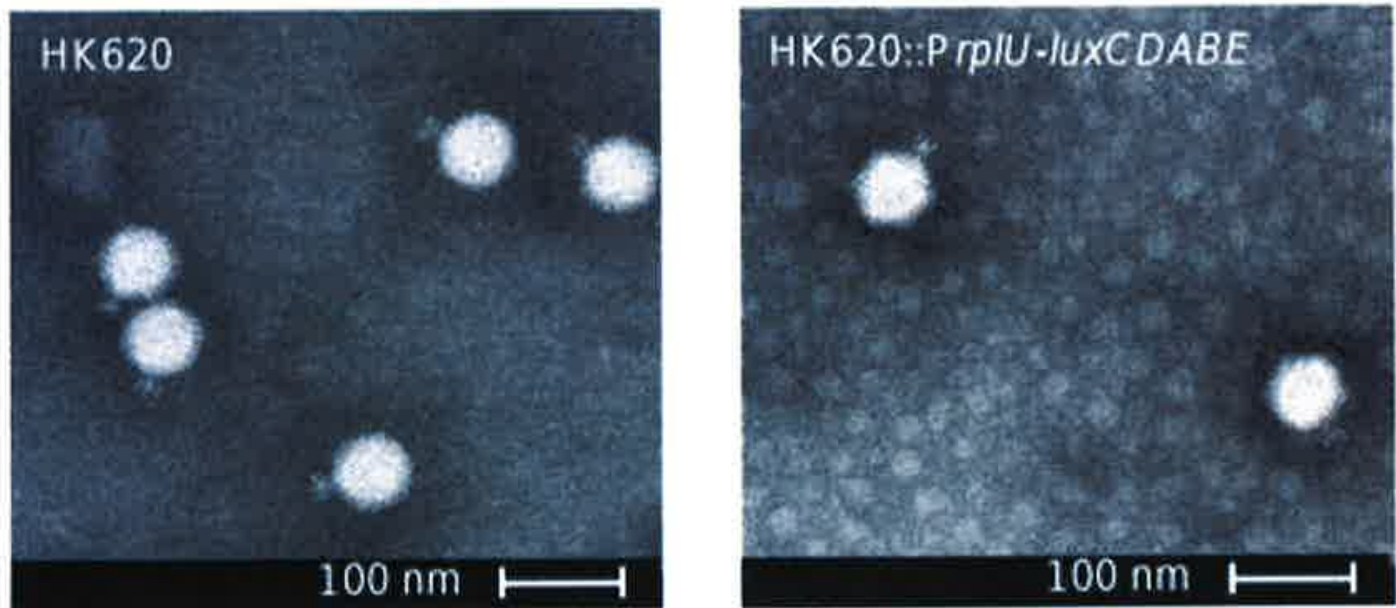

C

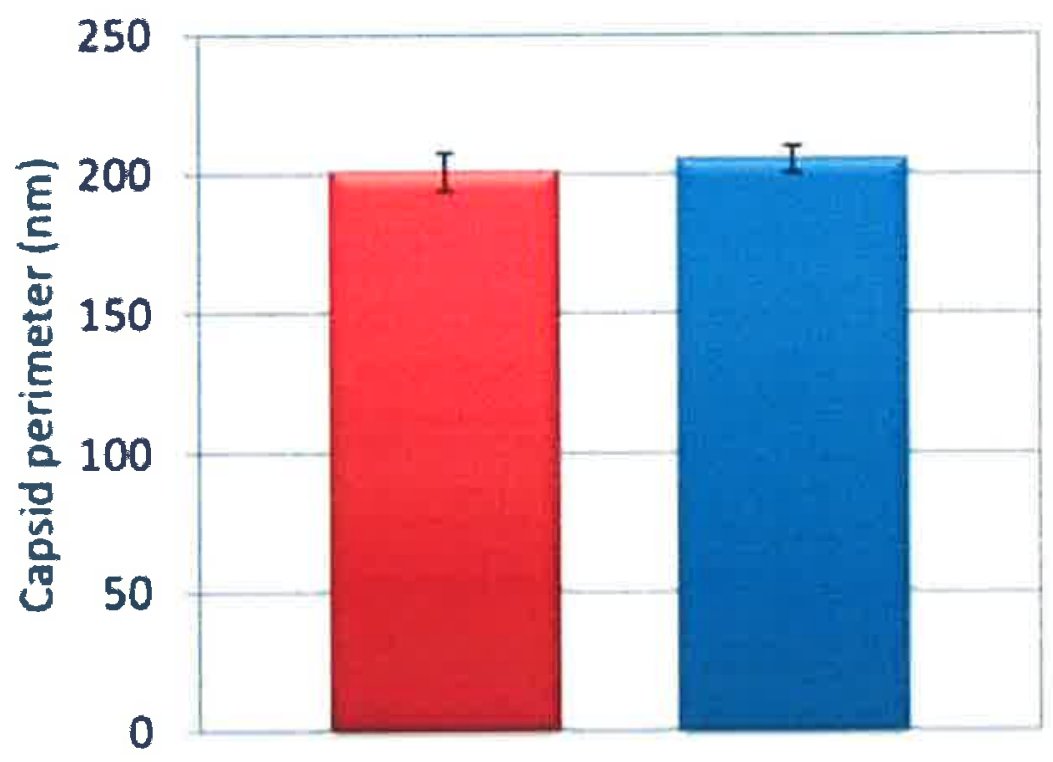


A

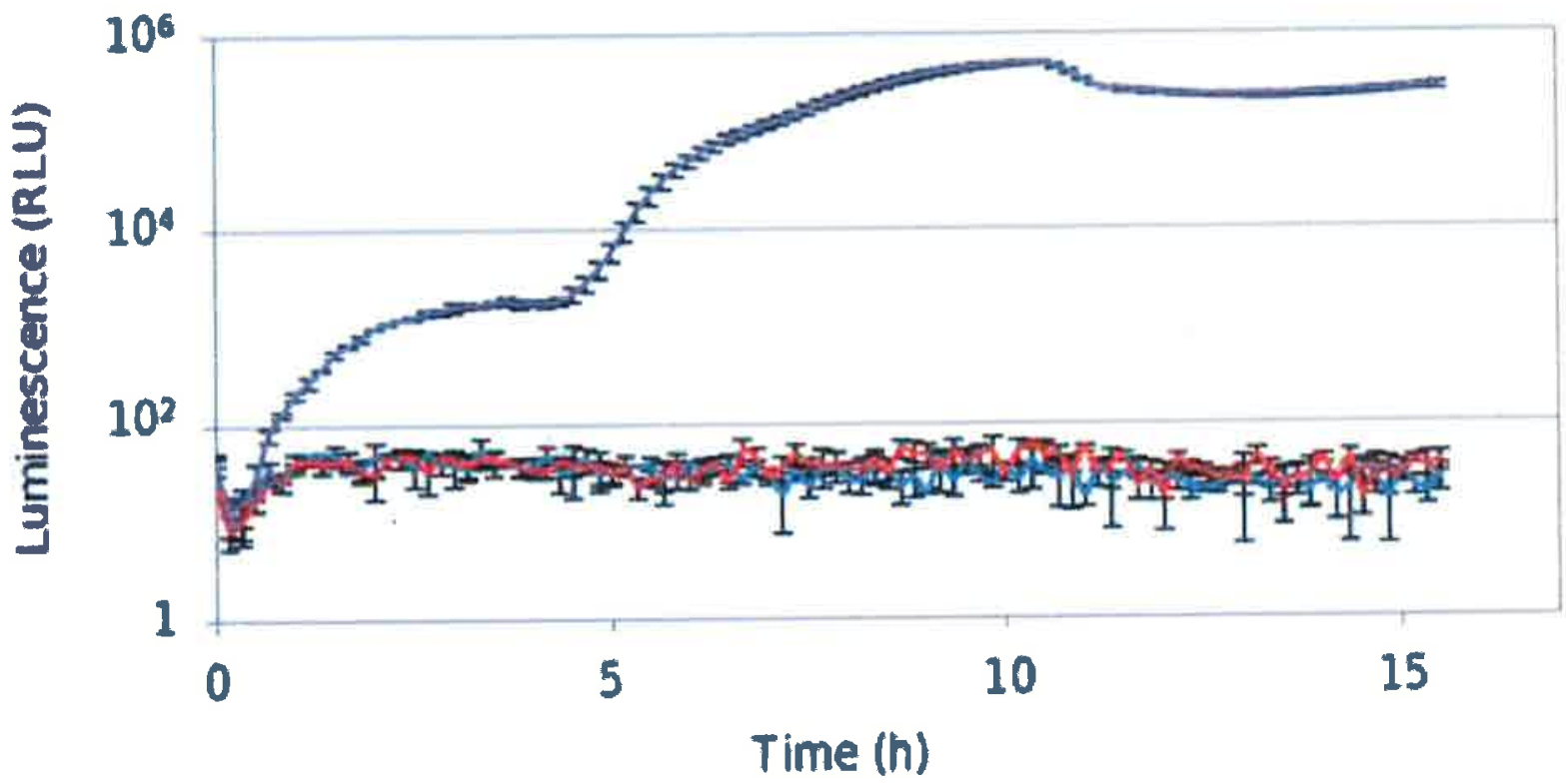

B

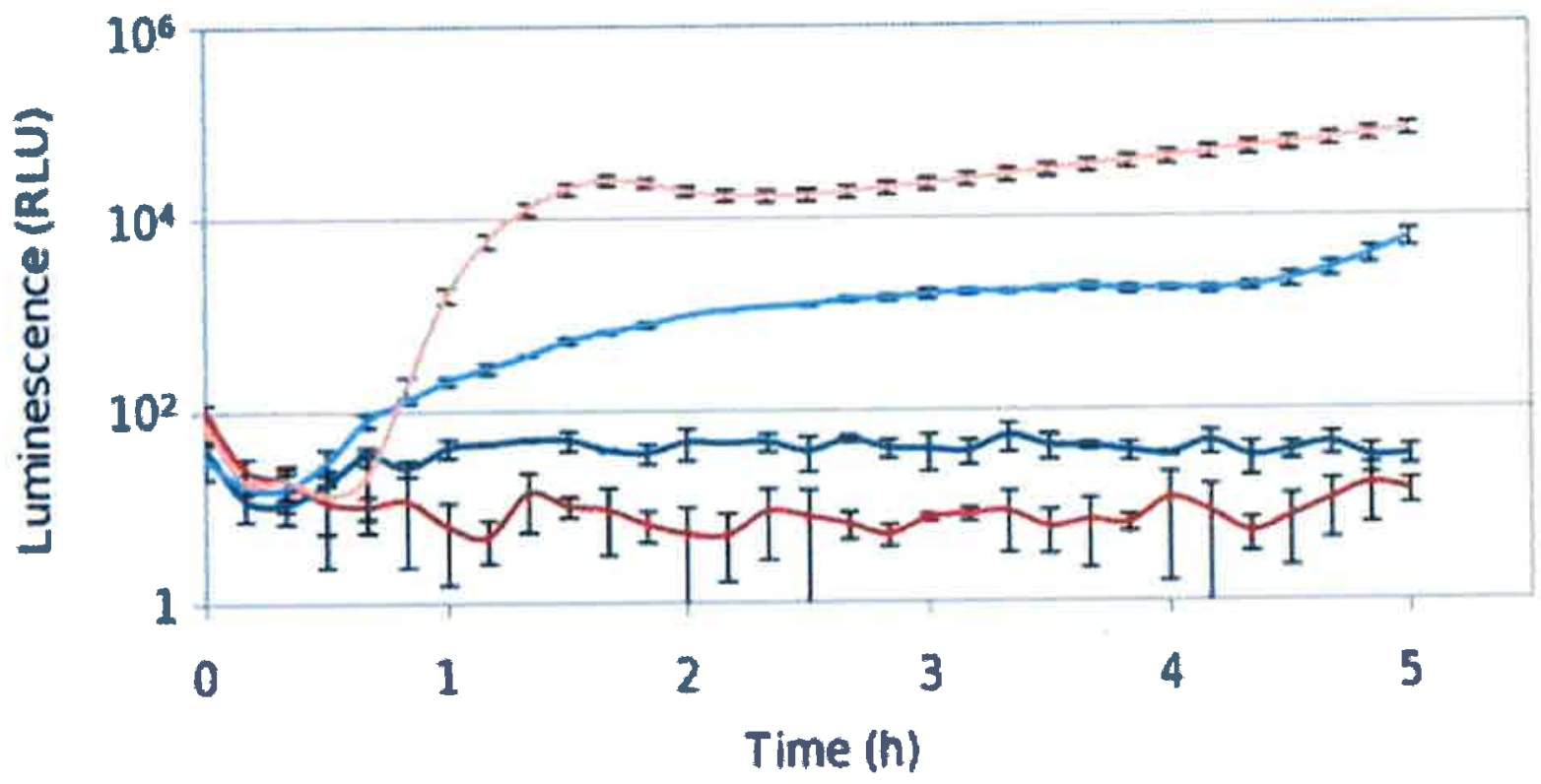



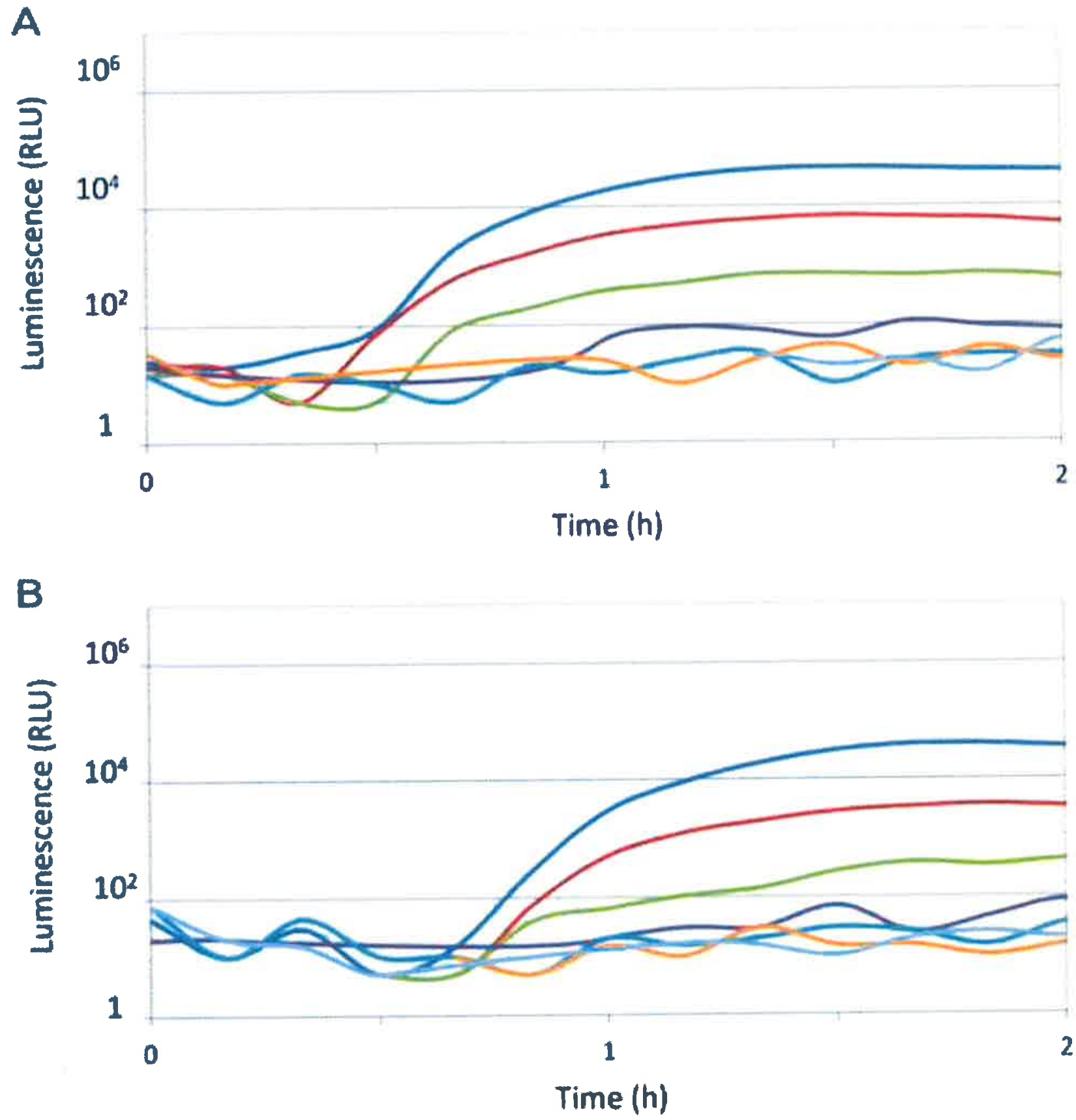